\title{
The Statistical Distribution and Determinants of Mother's Age at First Birth
}

\author{
Logubayom Anuwoje Ida*, Luguterah Albert \\ Department of Statistics, University for Development Studies, Navrongo, Ghana
}

Email address:

idalogubayom@yahoo.com (L. A. Ida)

To cite this article:

Logubayom Anuwoje Ida, Luguterah Albert. The Statistical Distribution and Determinants of Mother's Age at First Birth. American Journal of Theoretical and Applied Statistics. Vol. 4, No. 2, 2015, pp. 41-52. doi: 10.11648/j.ajtas.20150402.11

\begin{abstract}
The age at which child bearing begins, influences the number of children a woman bears throughout her reproductive period in the absence of any active fertility control. This study employed both parametric and non-parametric survival analysis techniques, with a cohort of women within the reproductive age (15-49 years), to determine the statistical distribution of the age at first birth of a woman from her time of birth and identify the significant prognostic factors determining the timing of first birth of Ghanaian women. Using data from the Ghana Demographic and Health Survey (GDHS), the study fitted several parametric Accelerated Failure Time models, from which the best parametric distribution for age at first birth was selected. The results revealed that, the average age at first birth was about 20 years, with more than $87.4 \%$ of the women having giving birth before they attained 25 years of age. The age at first birth among the Ghanaian women was best modeled by the log-logistic model. By this model, the age at which a woman had her first birth was determined, at the $10 \%$ significance level, by her Age at first marriage, her Educational level, her Wealth Status and whether or not the women practiced family planning before their first birth.
\end{abstract}

Keywords: Survival, First Birth, Accelerated Failure Time Models, Waiting Time, Age at First Birth

\section{Introduction}

The first visible outcome of the fertility process is the birth of the first child. First birth signifies the transition of a woman into motherhood with its related expectations and responsibilities. It plays a significant role in the future life of each woman and has a direct relationship with fertility. Censuses on world population revealed that, by 2050 the world's population is anticipated to reach 9.3 billion and nearly nine of every ten people will be living in a developing country (Hagman, 2001; Becker, 2001). Thus, the unprecedented growth of the population, caused by increasing fertility level which operates through the timing of first birth and the gap between births, pose several challenges for overall development (Abhiman, 2006). At this crucial juncture, scientific investigation of fertility is of paramount importance for population control, since it is influenced by a series of factors like socio-economic, demographic, behavioural, social customs, among others.

In order to investigate the nature of human fertility, it is important to study the timing of first birth. The relationship between age at first birth and overall fertility in developing countries is generally an unresearched area. Some fertility analysts generally assume that child bearing only occurs within marriage; therefore, they treat age at first marriage to be a major proximate determinant of fertility. This assumption holds true in most traditional societies, where births outside wedlock were not accepted and virginity was a prerequisite for marriage. This assumption however, does not hold true in modern times, where a large number of children are born outside marriage. Also, apart from biological components of fertility, the first birth interval is often prolonged due to the impact of some social and economic customs prevalent in certain societies, such as educational levels of women, employment status, contraceptives use, marital status, nature of menses, type of place of residence, region of residence among others.

Many studies reported voluntary childlessness among women as indication of their desire for independence, freedom and spontaneity (Fisher, 1991; Lisle, 1996; McAllister and Clarke, 1998). Delayed childbearing, and increased childlessness, is seen as the result of fundamental 
social, economic and cultural transformation which has changed the norms relating to family and reproduction. Recent sociological work similarly contends that, there has been a shift in personal values in a 'postmodern' context and a resultant shifting parental identity with consequences for fertility decline (Gillespie, 2001; MacInnes, 2003). The spread of access to modern contraception, and to a lesser extent the legalization of abortion, are also identified in literature as important determinants of fertility postponement. Many country-specific researchers such as Sobotka, (2004) and Murphy, $(1992,1993)$ provide evidence of the effect of contraception on the late start of fertility.

From an economic point of view, researchers have identified that, the optimal woman's age at first birth is an outcome of a plan for investments in human capital and a labour market career (Cigno and Ermisch, 1989; Cigno, 1991; Gustafson and Wetzels, 2000; Gustafsson, 2001). While from a traditional point of view, a man's career planning and ability to provide financially for his family would not give different results for optimal timing of the first child of his wife, for his wife with a career planning motive, she may see it optimal to postpone first motherhood to a point where her opportunity costs of child care in terms of her career have decreased, leading her to first complete her education and establish herself on the job market before becoming a mother. Many studies also identify educational attainment as a factor associated with fertility postponement. Empirical work along these theoretical lines, mostly analysing US data (Kasarda et al., 1986; Bloom and Trussell, 1984; Blackburn et al., 1993 among others) and some European countries as reviewed in Kravdal, (1994), all found a positive effect of women education on the timing of their first birth. Amuedo-Dorantes and Kimmel (2004) also established that, college educated women, who had their first child after they turned 30, earn more than similarly educated women, who had their first child before they were 30 . In recent decades, post-secondary education has undergone a massive expansion, and young adults in many parts of the world have spent an increasing proportion of time in education, with tertiary education constituting the main route to stable employment, adequate income and career development (Kohler et al., 2002). This expansion impacts on fertility directly, with the period of study evidently incompatible with family formation. Logubayom and Luguterah, (2013) also identified that, whether the wife had ever had an induced abortion or not, and her region of residence are the significant determinants of the waiting time to first birth after marriage in Ghana.

As documented in studies, the timing of first birth measured by the mother's age at first birth has a strong effect on both individual and aggregate levels of fertility, as well as broader implications for women's roles and social changes in general. This study therefore studied the reproductive behaviours of Ghanaian women; fitted a probability density function for the time to first birth of a woman and identified the significant prognostic factors of this time to first birth.

This research will serve as a guide to women on the timing of their birth in order to obtain their targeted family size as well as provide policy makers useful information for formulating policies on fertility.

\section{Materials and Methods of Data Analysis}

\subsection{Source of Data}

This study used secondary data from the 2008 Ghana Demographic and Health Survey (GDHS) obtained from the Ghana Statistical Service (GSS) and included only women of the reproductive age (15-49 years). The cohort of women were followed from birth to the time they had their own first child. Women within the cohort who actually gave birth before the end of the study were considered uncensored whiles those who had not yet given birth by the end of the study were considered as censored. In all, a total of 4916 women from all the 10 regions of Ghana and stratified by rural and urban communities were included in the study, with 3299 women uncensored, and a total of 1617 women censored.

\subsection{Variables in the Study}

The response variable in this study is the waiting time to first birth of a woman from her time of birth. The exogenous variables, which may be influential to a woman's age at first birth, were classified into demographic and socio-economic variables: These included the characteristics of the mother before the birth of her first child. The socio-economic factors included; her region of residence before her first birth (Northern or Southern Ghana), her highest level of education, Her religion, Her wealth index and Her type of place of residence, whiles the demographic factors consisted of whether a woman had ever terminated a pregnancy, Her age at first marriage and Her age at first intercourse.

\subsection{Data Analysis Techniques}

\subsubsection{Concepts of Survival Analysis}

Suppose $T$ represents a continuous, non-negative random variable representing the waiting time to first birth by a woman, then three main functions; the survival function $s(t)$, the hazard function, $h(t)$, and the probability density function, $f(t)$, describe the distribution of this survival time $T$. The Survival Function, $S(t)$, gives the probability of not giving birth beyond time $t$. The survival function at a given time $t$ is given as;

$$
\begin{aligned}
S(t) & =P(\text { a woman has not given birth to her first child by age } t \text { years }) \\
& =1-P(\text { a woman has given birth to her first child by time } t \text { years of age }) .
\end{aligned}
$$

$$
S(t)=P\{T>t\}=1-F(t)
$$


where $F(t)$ represents the cumulative density function at $T$ and is given as;

$$
F(t)=P[T<t]=\int_{0}^{t} f(t)=P[\text { that a woman had her first child before time } t]
$$

The Probability Density Function, $f(t)$, at time $t$, defined as the probability that a woman had her first child within a short interval per unit time, is given as:

$$
f(t)=\lim _{\Delta t \rightarrow 0} \frac{P[a \text { woman gives birth in the interval }(t, t+\Delta t)]}{\Delta t}=\lim _{\Delta t \rightarrow 0} \frac{P[t \leq T<t+\Delta t]}{\Delta t}
$$

The Hazard function, $h(t)$, gives the probability that a woman had her first birth within a small time interval, given that she survived up to the beginning of the interval. It can therefore be interpreted in this sense as the chance of a birth at time $t$. The hazard function is estimated as:

$$
\begin{gathered}
P(t)=\lim _{\Delta t \rightarrow 0} \frac{\begin{array}{c}
\text { woman had her first child in the time interval }(t, t+\Delta t) \\
\text { given that she had not given birth by time } t)
\end{array}}{\Delta t} \\
h(t)=\lim _{\Delta t \rightarrow 0} \frac{P[(t \leq T<t+\Delta t) / T \geq t]}{\Delta t} \\
h(t)=\frac{f(t)}{(1-F(t))}=\frac{f(t)}{S(t)}
\end{gathered}
$$

\subsubsection{Non-Parametric Comparism of Survival Distributions: Log-Rank Test}

In the analysis of survival data with censored individuals, the log-rank test provides an appropriate statistic to compare the survival functions of two or more groups. The Log-rank test by Peto and Peto, (1972) was therefore used in this study to test for the homogeneity of survival functions of the various categories of the independent variables. For a given $k$ factor group, the Log-rank test, tests the hypothesis;

$$
\begin{aligned}
& H_{o}: S_{1}(t)=S_{2}(t)=\cdots=S_{k}(t) \text { for all } t \\
& H_{1}: \text { not all } S_{j}(t) \text { are equal. } j=1,2, \ldots k .
\end{aligned}
$$

where $S_{j}(t)$ is the estimated survival function for the $j^{\text {th }}$ group.

Approximately, the Log-rank test is a chi-square statistic which compares the observed $\left(O_{j}\right)$ numbers of first births to the expected number $\left(E_{j}\right)$ of first births under the hypothesis. The chi-square test statistic is given by;

$$
\chi^{2}=\sum_{j=1}^{k} \frac{\left(o_{j}-E_{j}\right)^{2}}{E_{j}}
$$

where

$E_{j}=\sum_{\text {all } t} e_{j t}$ and $e_{j t}=\frac{n_{j t}}{\sum_{\text {all } j} n_{j t}} \times d_{t}$, where $n_{j t}$ is the number of women who had not given birth as at time $t$ for the $j^{\text {th }}$ group, $d_{t}$ is the total number of first births for all groups at time $t$. Thus, $d_{t}=\sum_{\text {all } j} d_{j t}$ also has an approximately chi-square distribution with $k-1$ degrees of freedom.

\subsubsection{Regression of Survival Data}

To identify the significant predictors of time to first birth of a woman from her birth, the study first fitted the semiparametric Cox proportional hazard regression and tested the proportionality assumption (of a constant hazard ratio over time) using the Schoenfeld residual. The Schoenfeld residual test involves testing of non-zero slope in a generalized linear regression of the scaled Schoenfeld residuals on time (Grambsch and Therneau, 1994). The Schoenfeld residuals are defined for each subject who failed and tested for individual covariates and globally, the null hypothesis of zero slopes; thus testing that the log hazard-ratio function is constant over time. A rejection of the null hypothesis of a zero slope indicates deviation from the proportional-hazards assumption. If the $\mathrm{PH}$ assumption holds for a particular covariate then the Schoenfeld residual for that covariate will not be related to survival time. The test revealed that, the assumption of proportionality was violated. This implies that the hazard functions for two different levels of a covariate are not proportional for all values of the time $t$. Since the hazard ratio changes with time, Accelerated Failure Time Models (AFT) was fitted to identify the prognostic factors of time to first birth.

\section{(i). Parametric Regression Model: Accelerated Failure \\ Time Models}

With parametric survival regressions, we assume that the survival time follows a given distribution and have a precise relationship with a set of covariates. An Accelerated failure time models is a parametric model that provides an alternative to the Cox proportional Hazard regression and assumes that the effects of a covariate is to accelerate or decelerate the life course of a survival time. The AFT model for a survival time assumes that, the log of the survival time $T$ and the covariates are a linear function given as;

$$
\log (T)=\theta_{0}+\sum_{i=1}^{p} \theta_{i} X_{i}+\sigma \varepsilon
$$

where $X_{i}, i=1, \ldots \ldots, p$ are the covariates, $\theta_{i}, i=0,1, \ldots \ldots, p$ are the regression coefficients, $\sigma$ is an unknown scale 
parameter and $\varepsilon$ is the random error term. The effect of the AFT model is to change the time scale by a factor of $\exp \left(-X_{i} \beta\right)$. Depending on whether this factor is greater or less than one (1), time is either accelerated or decelerated.

The error term is distributed as $\log \left(T_{0}\right)$ which is independent of $\theta$. This reduces the AFT model to a regression model with $\sum_{j=1}^{p} \theta_{i} X_{i}$ as fixed effect and $\varepsilon$ as random effects (noise). Different distributions of the random term leads to different distributional form of $T_{0}$. The AFT models are purely parametric, thus the probability distribution is specified for $\log \left(T_{0}\right)$. Five main parametric AFT models; the Weibull distribution, Exponential distribution, Log-logistic distribution, Log-normal distribution and Gamma distribution were assessed to describe the relationship between the survival time $T$ and the set of covariates, from which the best model was selected using appropriate model selection criteria. In AFT models, positive coefficient increases the log survival and increases expected duration whiles negative parameter estimate decreases log survival and decreases expected waiting time.

For the AFT model given in equation (6), a Weibull distribution will have the hazard, survival and density functions given as;

$$
\begin{gathered}
h\left(t, \lambda_{i}, \gamma\right)=\gamma \lambda_{i} t^{\gamma-1} \\
f\left(t, \lambda_{i}, \gamma\right)=\lambda_{i} \gamma t^{\gamma-1} \exp \left(-\lambda_{i} t^{\gamma}\right) \\
s\left(t, \lambda_{i}, \gamma\right)=\exp \left(-\lambda_{i} t^{\gamma}\right)
\end{gathered}
$$

where $\gamma=1 / \sigma$ is the shape parameter. If $\gamma=1$, then the Weibull functions reduces to the exponential distributions with survival, hazard and density functions given as;

$$
\begin{gathered}
h\left(t, \lambda_{i}, \gamma\right)=\lambda_{i}=\exp \left(-X_{i} \beta\right) \\
f\left(t, \lambda_{i}, \gamma\right)=\lambda_{i} \exp \left(-\lambda_{i} t\right) \\
s\left(t, \lambda_{i}, \gamma\right)=\exp \left(-\lambda_{i} t\right)
\end{gathered}
$$

where $\lambda_{i}=\exp \left(-X_{i} \beta\right)$.

If the error term follows the Log-Logistic Distribution, the survival, hazard and density functions are given as;

$$
\begin{aligned}
& s\left(t, \lambda_{i}\right)=\left\{1+\left(\lambda_{i} t\right)^{1 / s}\right\}^{-1} \\
& h\left(t, \lambda_{i}, p\right)=\lambda_{i}{ }^{1 / s} t^{((1 / s)-1)} /{ }_{s}\left\{1+\left(\lambda_{i} t\right)^{1 / s}\right\} \\
& f\left(t, \lambda_{i}, p\right)=\lambda_{i}{ }^{1 / s} t^{\left(\left({ }^{1} / s\right)-1\right)} /{ }_{s}\left\{1+\left(\lambda_{i} t\right)^{1 / s}\right\}^{2}
\end{aligned}
$$

$\lambda_{i}=\exp \left(-X_{i} \beta\right), s$ is a scale parameter, $s=1 / \sigma$. When the shape parameter of the log-logistic is less or equal to one, the hazard rate decreases monotonically and when it is greater than one, it increases from zero to a maximum and then decreases to zero.

For the Logistic model, the odds of an individual surviving longer than time $t$ are given as;

$$
s\left(t_{i}, b\right) /\left[1-s\left(t_{i}, b\right)\right] \text {. Given } O R_{I} \text { and } O R_{j} \text { as the odds of }
$$

survival for individuals $i$ and $j$, then the $\log$ of odds ratio is;

$$
\operatorname{In}\left(O R_{I} / O R_{j}\right)=1 / \sigma \sum_{k=1}^{p} \theta_{k}\left(X_{k i}-X_{k j}\right)
$$

This ratio is depended on time hence the log-logistic model is a proportional odds model (Elisa and John, 2003).

For a Lognormal distribution, $\varepsilon$ is a standard normal random variable with survival, density and hazard functions given as;

$$
\begin{gathered}
s(t)=1-\phi\{\operatorname{In}(t)-\mu) / \sigma\} \\
f(t)=\frac{1}{t \sigma \sqrt{2 \Pi}} \exp \left[-1 / 2 \sigma^{2}\{\operatorname{In}(t)-\mu\}^{2}\right. \\
h(t)=\frac{\frac{1}{t \sigma \sqrt{2 \Pi}} \exp \left[-1 / 2 \sigma^{2}\{\operatorname{In}(t)-\mu\}^{2}\right.}{1-\phi\left\{^{\operatorname{In}(t)-\mu)} / \sigma\right\}}
\end{gathered}
$$

where $\phi$ is the cumulative density function of the standard normal distribution. The lognormal regression is implemented by setting $\mu_{i}=X_{i} \beta$ and treating the standard deviation, $\sigma$ as an ancillary parameter to be estimated from the data.

The log-logistic and log-normal AFT models are appropriate for data with non-monotonic unimodal hazards rates; thus initially increasing and then decreasing rates. The hazard rate of the log-normal AFT model is similar to that for the log-logistic when the shape parameter is less than one.

For a Gama Distribution, the density function is;

$$
\begin{gathered}
f\left(t, \lambda_{i}\right)=\frac{\lambda_{i} p(\lambda t)^{p k-1} \exp \left(-\lambda_{i} t\right)^{p}}{\Gamma(k)} \\
\lambda_{i}=\exp \left(-X_{i} \beta\right)
\end{gathered}
$$

where $p$ and $k$ are shape parameters. The gamma model is good for adjudicating between (some) competing parametric models. Forms of the shape parameters are;

- $\quad k=1$, then we have a Weibull distribution.

- $k=p=1$, we have an exponential.

- $\quad$ For $k=0$, the log-normal is implied.

- $p=1$, we have a gamma distribution.

\section{(ii). Selection between Competing Parametric Models and Goodness of Fit Test}

This study used the Akaike Information Criterion, AIC (Akaike, 1974), the Akaike Information Criterion Corrected, AICC, the Schwarz Bayesian Information Criterion, BIC (Schwarz, 1978) and the log-likelihood value to select among the five fitted parametric models, the best model that described the relationship between the survival time and the covariates considered. The parametric model with the least AIC, BIC and the largest log-likelihood value provided the best fit of the relationship. 


\section{Results and Discussion}

\subsection{Descriptive Statistics}

Table 1 shows the frequency distributions of the age at first birth among the women in the study. A total of 3299 representing $67.1 \%$ of the entire respondents had at least one births. About $53 \%$ of the 3299 women, representing more than half of the study population had their first baby before they attained 20 years of age. Also, about $35 \%$ of the women had their first birth in their early 20s (20-24 years), about $13 \%$ of them in their late 20 's and only $2.5 \%$ of them had their first birth at 30 years and over. The minimum age at first birth was 15 years with the maximum age being 43 years: The mean age at first birth of about 20 years. The age at first birth is positively skewed $(1.002( \pm 0.043))$ and leptokurtic in distribution.

Table 1. Distribution of mother's age at first birth.

\begin{tabular}{lll}
\hline Birth age & Frequency & Percentage \\
\hline$<20$ & 1733 & 52.5 \\
$20-24$ & 1151 & 34.9 \\
$25-29$ & 334 & 10.1 \\
$30-34$ & 69 & 2.1 \\
$35^{+}$ & 12 & 0.4 \\
Total & 3299 & 100 \\
Overall Mean Age at First Birth & 19.91 \\
Minimum age at first birth & 15 \\
Maximum age at first birth & 43 \\
Skewness & $1.002( \pm 0.043)$ \\
Excess Kurtosis & 1.564 \\
\hline
\end{tabular}

\subsection{Log-Rank Test}

Table 2 presents information on the life table estimate of the time to first birth: The test of homogeneity of survival differentials among the women of the various categories of socio-economic and demographic factors considered in this study, as well as their average waiting time to first birth are shown. The log rank test, established the existence of a highly significant difference in the survival times of women living in urban and rural areas $(P$-value $=<0.0001)$ : Averagely, women living in urban settings had a 3 year longer waiting time (low risk) to birth than those living in rural settings. Also, Women living in Northern Ghana averagely gave birth about a year earlier than women in the Southern part of Ghana (mean of 19.302 for Northern Ghana and 20.229 for Southern Ghana) and this was statistically significant at the $10 \%$ significance level $(P$-Value $=0.0110)$. Furthermore, the time to first birth of the women differed significantly by Educational level $(P$-value $=0.0110)$, Wealth status of a family $(P$-value $<0.0001)$, Age at marriage $(P$ value $<0.0001)$ and Age at first intercourse $(P$-value $=0.0001)$ as clearly shown by the log-rank tests. As shown by the Mean survival, the higher the educational level of the woman, the longer the waiting time to her first birth: $73 \%$ of postsecondary level women had not given birth before attaining 30 years of age. Also, women from richer families waited longer to have their first birth than women from poor homes. While only about $16 \%$ of women from poor financial backgrounds had not given birth at 29 years, more than half $(51 \%)$ of women from the richest families had not given birth by this age. The longer a woman waited to have her first sex, or first marriage, the longer her waiting time to have her first baby: Time to first birth also differed significantly by the type of contraceptive a woman used.

However, Time to first birth did not differ by Religion nor Ever terminated a pregnancy at the $10 \%$ significance level.

Table 2. Life table and Log-rank test of time duration to first birth of the women.

\begin{tabular}{|c|c|c|c|c|c|c|c|c|c|}
\hline \multirow{2}{*}{ Variables } & \multicolumn{6}{|c|}{ Proportion not giving birth at years } & \multirow{2}{*}{$\begin{array}{l}\text { Mean Survival } \\
\text { (Years) }\end{array}$} & \multirow{2}{*}{$\begin{array}{l}\text { Log-rank } \\
\text { Statistic }\end{array}$} & \multirow[t]{2}{*}{$p$-value } \\
\hline & $<20$ & $20-24$ & $25-29$ & $30-34$ & 35-39 & $>39$ & & & \\
\hline \multicolumn{10}{|c|}{ Demographic Factors } \\
\hline \multicolumn{10}{|c|}{ Contraceptives type used } \\
\hline Never used & 0.968 & 0.553 & 0.224 & 0.149 & 0.090 & 0.067 & 21.921 & & \\
\hline Modern types & 0.971 & 0.566 & 0.299 & 0.085 & 0.036 & 0.028 & 22.479 & 27.408 & $0.0670 * *$ \\
\hline Folkloric types & 1.000 & 0.833 & 0.463 & 0.071 & 0.022 & 0.011 & 22.444 & & \\
\hline Traditional types & 0.973 & 0.636 & 0.275 & 0.126 & 0.067 & 0.048 & 22.297 & & \\
\hline \multicolumn{10}{|c|}{ Age at first intercourse (grouped) } \\
\hline$\leq 18$ & 0.959 & 0.440 & 0.156 & 0.063 & 0.0462 & 0.039 & 20.382 & & \\
\hline $19-25$ & 0.998 & 0.905 & 0.456 & 0.201 & 0.104 & 0.08 & 25.634 & 535.698 & $0.0001 * * *$ \\
\hline$\geq 26$ & 0.977 & 0.977 & 0.907 & 0.472 & 0.157 & 0.157 & 28.904 & & \\
\hline \multicolumn{10}{|c|}{ Ever terminated a pregnancy } \\
\hline Yes & 0.957 & 0.564 & 0.236 & 0.121 & 0.082 & 0.074 & 21.947 & 0.662 & 0.4160 \\
\hline No & 0.972 & 0.623 & 0.274 & 0.113 & 0.053 & 0.033 & 22.165 & & \\
\hline \multicolumn{10}{|c|}{ Age at marriage (grouped) } \\
\hline$\leq 19$ & 0.924 & 0.224 & 0.040 & 0.016 & 0.008 & 0.008 & 18.196 & & \\
\hline $20-25$ & 0.993 & 0.830 & 0.234 & 0.048 & 0.030 & 0.022 & 22.457 & 1378.600 & $<0.0001 * * *$ \\
\hline $26-30$ & 0.992 & 0.875 & 0.775 & 0.378 & 0.128 & 0.092 & 27.780 & & \\
\hline$>30$ & 1.000 & 0.692 & 0.615 & 0.462 & 0.385 & 0.154 & 27.615 & & \\
\hline \multicolumn{10}{|c|}{$\begin{array}{l}\text { Socio-economic factors } \\
\text { type of place of residence }\end{array}$} \\
\hline Rural & 0.960 & 0.540 & 0.184 & 0.065 & 0.030 & 0.020 & 20.876 & 239.370 & $<0.0001 * * *$ \\
\hline Urban & 0.982 & 0.705 & 0.372 & 0.182 & 0.107 & 0.086 & 23.699 & & \\
\hline Region & & & & & & & & & \\
\hline
\end{tabular}




\begin{tabular}{|c|c|c|c|c|c|c|c|c|c|}
\hline \multirow{2}{*}{ Variables } & \multicolumn{6}{|c|}{ Proportion not giving birth at years } & \multirow{2}{*}{$\begin{array}{l}\text { Mean Survival } \\
\text { (Years) }\end{array}$} & \multirow{2}{*}{$\begin{array}{l}\text { Log-rank } \\
\text { Statistic }\end{array}$} & \multirow[t]{2}{*}{$p$-value } \\
\hline & $<20$ & $20-24$ & 25-29 & 30-34 & 35-39 & $>39$ & & & \\
\hline Northern Ghana & 0.952 & 0.559 & 0.200 & 0.067 & 0.026 & 0.011 & 19.302 & 44.385 & $0.0110^{* * *}$ \\
\hline Southern Ghana & 0.976 & 0.632 & 0.291 & 0.133 & 0.076 & 0.061 & 20.229 & & \\
\hline \multicolumn{10}{|l|}{ Religion } \\
\hline Christianity & 0.974 & 0.632 & 0.291 & 0.131 & 0.073 & 0.057 & 22.434 & & \\
\hline Islam & 0.965 & 0.609 & 0.243 & 0.108 & 0.059 & 0.029 & 21.942 & 87.835 & 0.1010 \\
\hline Traditionalist & 0.940 & 0.467 & 0.131 & 0.029 & 0.005 & 0.008 & 19.797 & & \\
\hline \multicolumn{10}{|l|}{ Educational level } \\
\hline No-education & 0.938 & 0.469 & 0.135 & 0.039 & 0.019 & 0.007 & 19.956 & & \\
\hline Primary level & 0.956 & 0.471 & 0.161 & 0.057 & 0.034 & 0.028 & 20.268 & & \\
\hline Secondary level & 0.989 & 0.724 & 0.352 & 0.169 & 0.092 & 0.076 & 23.441 & 552.900 & $0.0010^{* * *}$ \\
\hline Higher & 0.989 & 0.933 & 0.731 & 0.402 & 0.236 & 0.236 & 27.470 & & \\
\hline \multicolumn{10}{|l|}{ Wealth status } \\
\hline Poorest family & 0.950 & 0.511 & 0.159 & 0.051 & 0.015 & 0.007 & 20.348 & & \\
\hline Poorer family & 0.949 & 0.523 & 0.167 & 0.055 & 0.022 & 0.011 & 20.381 & & \\
\hline Middle income family & 0.977 & 0.571 & 0.204 & 0.068 & 0.049 & 0.032 & 21.264 & 408.450 & $<0.0001 * * *$ \\
\hline Richer family & 0.984 & 0.654 & 0.293 & 0.147 & 0.088 & 0.063 & 22.732 & & \\
\hline Richest family & 0.988 & 0.803 & 0.505 & 0.257 & 0.153 & 0.144 & 25.112 & & \\
\hline
\end{tabular}

*** means significant at $5 \%$ significance level

** Means significant at $10 \%$ significance level

\subsection{Cox Proportional Hazard Model}

Table 3 presents the results of the Schoenfeld residuals test of the proportionality assumption of the hazard ratio of individuals when the Cox model was fitted. A significant test statistic was obtained for some of the covariates at the $10 \%$ significance level; Age at first marriage, Ever terminated a pregnancy, Type of Contraception used, women living in urban areas, Region of residence of a woman, Primary and Secondary levels of Educational, as well as the global test. Thus, the assumption of proportionality of the hazard ratio of individuals was violated for these categories as well as the overall Cox model. . This implies, a single hazard ratio describing the effect of these variables on the survival time will not be appropriate.

Table 3. Schoenfeld Residuals Test for Proportionality Assumption of Cox Model.

\begin{tabular}{lllll}
\hline Variables & Rho & \multicolumn{1}{c}{$\chi^{2}$} & DF & p-value \\
\hline $\begin{array}{l}\text { Demographic factors } \\
\text { Age at first marriage }\end{array}$ & 0.467 & 692.060 & 1 & $0.000^{* * *}$ \\
Age at first intercourse & 0.023 & 1.730 & 1 & 0.188 \\
$\begin{array}{l}\text { Ever terminated a pregnancy } \\
\text { No }\end{array}$ & -0.078 & 19.170 & 1 & $0.000^{* * *}$ \\
Yes & -0.005 & 0.100 & 1 & 0.756 \\
Contraception type & & & & \\
Never used & 0.035 & 3.840 & 1 & $0.080^{* *}$ \\
Folkloric methods & 0.049 & 7.770 & 1 & $0.005^{* * *}$ \\
Modern types & 0.099 & 32.350 & 1 & $0.000^{* * *}$ \\
Natural methods & 0.023 & 8.230 & 1 & $0.004^{* * *}$ \\
Socio-economic factors & & & & \\
Type of place of residence & & & & \\
Rural & -0.009 & 0.220 & 1 & 0.639 \\
Urban & $0 . .022$ & 0.370 & 1 & $0.000^{* * *}$ \\
Region & & & & \\
Northern Ghana & 0.044 & 6.510 & 1 & $0.011^{* * *}$ \\
Southern Ghana & 0.035 & 8.350 & 1 & $0.020^{* * *}$ \\
\hline
\end{tabular}

\begin{tabular}{lllll}
\hline Variables & Rho & $\chi^{2}$ & DF & p-value \\
\hline Educational level & & & & \\
No education & -0.010 & 0.330 & 1 & 0.567 \\
Primary & 0.054 & 9.340 & 1 & $0.002^{* * *}$ \\
Secondary & 0.041 & 5.250 & & $0.022^{* * *}$ \\
Post-Secondary & 0.017 & 0.910 & 1 & 0.341 \\
Wealth status & & & & \\
Poorest & 0.026 & 2.110 & 1 & 0.146 \\
Poorer & 0.006 & 0.030 & 1 & 0.867 \\
Middle & -0.014 & 0.650 & 1 & 0.420 \\
Richer & -0.021 & 1.310 & 1 & 0.253 \\
Religion & & & & \\
Christianity & -0.008 & 0.180 & 1 & 0.671 \\
Islamic & 0.022 & 1.560 & 1 & 0.212 \\
Global Test & & 839.900 & 19 & $0.000^{* * *}$ \\
\hline
\end{tabular}

*** means significant at 5\% significance level; proportionality assumption is violated

** means significant at $10 \%$ significance level; proportionality assumption is violated

\subsection{Accelerated Failure Time Models Analysis}

The five parametric models fitted, with covariates, to describe appropriately the relationship between the prognostic variables considered and the waiting time to first birth of Ghanaian women are shown in Table 4. Although, the models for the various distributions were all statistically significant at the $5 \%$ significant level, a check on the AIC, AICC, BIC and the Log-likelihood statistics showed that the Log-logistic survival model, best described the time to first birth since it had the least AIC, AICC and BIC values and the maximum $\log$ likelihood value ( $\mathrm{AIC}=2898.69$, $\mathrm{AICC}=2898.48, \mathrm{BIC}=2.788 .54, \mathrm{LL}=1467.343)$.

Table 4. Fitted Parametric Models with Covariates.

\begin{tabular}{llllll}
\hline Distribution & AIC & AICC & BIC & Log Likelihood & $\boldsymbol{\chi}^{2}$ \\
\hline Weibull & -818.793 & -818.590 & -708.650 & 427.396 & 1765.080 \\
Exponential & 6856.478 & 6856.660 & 6960.500 & -3411.239 & $0.000^{* * *}$ \\
\hline
\end{tabular}




\begin{tabular}{|c|c|c|c|c|c|c|}
\hline Distribution & AIC & AICC & BIC & Log Likelihood & $\chi^{2}$ & $p$-value \\
\hline Log-normal & -2226.310 & -2226.100 & -2116.170 & 1131.156 & 2100.690 & $0.000 * * *$ \\
\hline Log-logistic & $-2898.690 *$ & $-2898.480 *$ & $-2788.540 *$ & $1467.343^{*}$ & 2702.390 & $0.000 * * *$ \\
\hline Gama & -2231.600 & -2231.400 & -2115.340 & 1134.801 & 2321.810 & $0.000 * * *$ \\
\hline
\end{tabular}

*implies model selected by model selection criteria

*** implies model is significant at $5 \%$ significance level

Table 5 therefore presents the results of the overall effects of each prognostic variable considered, on the time to first birth using the Log-logistic model. The results showed that, among the nine covariates describing the women's age at first birth, the Age of a woman at first marriage, her Educational level and Type of contraceptive used, were significant determinants of a woman's time to first birth at the $5 \%$ significance levels, while the Wealth level of a woman's family was significant at the $10 \%$ significance level. However, the Age at first intercourse of a woman, the Region of her residence, her Religious affiliation, whether she had ever terminated a pregnancy before her first birth or not and the Type of place of her residence, were not significant determinants of her waiting time to first birth.

Table 5. Analysis of Effects of Variables on Birth Time from Log-logistic Model.

\begin{tabular}{llll}
\hline Effects & DF & Wald $\boldsymbol{\chi}^{\mathbf{2}}$ & $\boldsymbol{p}$-value \\
\hline Age at first Marriage & 1 & 4055.829 & $0.000^{* * *}$ \\
Age at first intercourse & 1 & 0.133 & 0.716 \\
Ever terminated a Pregnancy & 1 & 0.183 & 0.669 \\
contraceptives type use & 3 & 11.379 & $0.010^{* * *}$ \\
wealth index & 4 & 8.054 & $0.089 * *$ \\
educational Level & 3 & 39.750 & $0.000^{* * *}$ \\
Region & 1 & 2.442 & 0.118 \\
Religion & 2 & 1.964 & 0.375 \\
Type of place of residence & 1 & 0.084 & 0.772 \\
\hline
\end{tabular}

*** means variable is significant at $5 \%$ significance level

** means variable is significant at $10 \%$ significance level

The parameter estimate of the Log-logistic model as shown in Table 6 revealed that, the age at marriage is significantly positively related to the time to first birth (estimate $=0.039, p-$ value $=0.000 \quad$ ) at the $5 \%$ significance level implying that, delayed marriage prolonged the expected time to first birth. A woman's time to first birth is increased by a rate of about $67 \%$ for every one year delay in marrying. In comparison to women who had secondary level education, women with no formal education and those with primary education had a significantly shorter waiting time to first birth, decreasing by $31.5 \%$ and $28.1 \%$ respectively: Women with post-secondary education had their time to first birth significantly prolonged by $81.1 \%$ as compared to those with secondary Education (survival odds of 0.685 and 0.719 respectively). This is consistent with the log-rank test which revealed a significant difference in survival times between the various categories of educational levels: Thus, higher education means longer waiting time. The results of the significant impact of education on age at first birth is consistent with views of other researchers such as Kasarda et al.,1986; Bloom and Trussell, 1984; Blackburn et al., 1993; De Wit and Rajulton 1991; Kravdal, 1994; Gustafsson and Wetzels, 2000; Amuedo-Dorantes and Kimmel (2004); and Kohler et al., 2002. These studies revealed that, higher educational attainment results in a postponement of childbirth and consequently resulting in higher ages at first birth. This may be due to the fact that tertiary education now constitutes a main stance for a more stable and better employment in many societies and many women who want a stable career will spend an increasing portion of their time in education at the expense of child birth Higher education impacts fertility directly, with the period of study evidently incompatible with family formation and child birth. Education attainment may as well impact age at first birth through the timing of first marriage. This is because a focus in obtaining higher education may lead to delayed in time of marriage, which may as well lead to a postponement of childbirth. Its impact can also be viewed from the careerplanning and consumption-smoothing motive as demonstrated by Hotz and Willis, (1997), that generally, a woman who aspires to a better career will have to finish education and have well recognized job before childbirth.

Table 6. Parameter Estimates of Log-logistic Model.

\begin{tabular}{|c|c|c|c|c|c|c|c|c|}
\hline \multirow{2}{*}{ Explanatory variables } & \multirow{2}{*}{ DF } & \multirow{2}{*}{ Estimate } & \multirow{2}{*}{ SE } & \multirow{2}{*}{$\chi^{2}$} & \multirow{2}{*}{$p$-value } & \multicolumn{2}{|c|}{$95 \%$ CL for estimate } & \multirow{2}{*}{$\begin{array}{l}\text { Odds of } \\
\text { Giving birth }\end{array}$} \\
\hline & & & & & & Lower & Upper & \\
\hline Intercept & 1 & 2.289 & 0.018 & 17120.100 & $0.000 * * *$ & 2.255 & 2.323 & \\
\hline \multicolumn{9}{|l|}{ Demographic factors } \\
\hline Age at first marriage & 1 & 0.039 & 0.001 & 4055.830 & $0.000 * * *$ & 0.038 & 0.040 & 1.673 \\
\hline Age at first intercourse & 1 & 0.003 & 0.000 & 0.130 & 0.716 & -0.000 & 0.004 & 1.034 \\
\hline \multicolumn{9}{|c|}{ Ever terminate a pregnancy (compared with yes) } \\
\hline No & 1 & -0.002 & 0.006 & 0.180 & 0.669 & -0.013 & 0.009 & 0.969 \\
\hline \multicolumn{9}{|c|}{ Contraceptives type used (compared with Natural) } \\
\hline Never used & 1 & -0.002 & 0.008 & 0.040 & 0.841 & -0.018 & 0.015 & 0.978 \\
\hline Folkloric methods & 1 & 0.127 & 0.070 & 3.260 & $0.071 * *$ & -0.011 & 0.264 & 1.635 \\
\hline Modern types & 1 & 0.014 & 0.008 & 2.950 & $0.086^{* *}$ & -0.030 & 0.002 & 1.203 \\
\hline \multicolumn{9}{|c|}{ Socio-economic factors } \\
\hline \multicolumn{9}{|c|}{ Type of place of residence (compared with Urban area) } \\
\hline Rural & 1 & -0.002 & 0.006 & 0.080 & 0.772 & -0014 & 0.010 & 0.976 \\
\hline \multicolumn{9}{|c|}{ Region (Compared with southern Ghana) } \\
\hline Northern Ghana & 1 & -0.010 & 0.006 & 2.440 & 0.118 & -0.003 & 0.022 & 0.878 \\
\hline \multicolumn{9}{|c|}{ Educational Level (compared with secondary) } \\
\hline
\end{tabular}




\begin{tabular}{|c|c|c|c|c|c|c|c|c|}
\hline \multirow{2}{*}{ Explanatory variables } & \multirow{2}{*}{ DF } & \multirow{2}{*}{ Estimate } & \multirow{2}{*}{ SE } & \multirow{2}{*}{$\chi^{2}$} & \multirow{2}{*}{$p$-value } & \multicolumn{2}{|c|}{$95 \%$ CL for estimate } & \multirow{2}{*}{\begin{tabular}{l|} 
Odds of \\
Giving birth
\end{tabular}} \\
\hline & & & & & & Lower & Upper & \\
\hline No education & 1 & -0.025 & 0.006 & 14.810 & $0.000^{* * *}$ & -0.037 & -0.0122 & 0.685 \\
\hline Primary & 1 & -0.028 & 0.006 & 21.750 & $0.000^{* * *}$ & -0.040 & -0.017 & 0.719 \\
\hline Post-Secondary & 1 & 0.045 & 0.014 & 10.890 & $0.001 * * *$ & 0.018 & 0.071 & 1.811 \\
\hline \multicolumn{9}{|c|}{ Wealth status (compared with richest) } \\
\hline Poorest & 1 & -0.018 & 0.009 & 3.420 & $0.064 * *$ & -0.033 & 0.001 & 0.788 \\
\hline Poorer & 1 & -0.017 & 0.008 & 5.140 & $0.023 * * *$ & -0.033 & -0.002 & 0.799 \\
\hline Middle & 1 & -0.016 & 0.008 & 4.580 & $0.032 * * *$ & -0.032 & -0.001 & 0.807 \\
\hline Richer & 1 & -0.004 & 0.008 & 0.340 & $0.041 * * *$ & -0.019 & 0.010 & 0.943 \\
\hline \multicolumn{9}{|c|}{ Religion (compared with traditionalist) } \\
\hline Christianity & 1 & 0.001 & 0.008 & 0.010 & 0.903 & -0.014 & 0.016 & 1.138 \\
\hline Islamic & 1 & 0.010 & 0.009 & 1.230 & 0.268 & -0.007 & 0.027 & 1.012 \\
\hline Scale parameter & 1 & 0.075 & 0.001 & & & 0.073 & 0.078 & \\
\hline Shape parameter & 1 & 13.298 & & & & & & \\
\hline
\end{tabular}

*** implies significant at 5\% significance level

**implies significant at $10 \%$ significance level

Compared with the richest families, women from the poorest, poorer, middle and richer financial background are associated with lower waiting times. The odds of the survival show clearly that the poorer the family background, the earlier a woman's first birth is likely to be. This may be due to the fact that, richer families are mostly characterised by either husband or wife or both focusing on obtaining better education and consequently better jobs or businesses, and also have better family planning, thus delay childbirth. Also, most women from poorer homes may be under pressure from themselves and parents to leave and start their own family.

Whether a woman had ever used contraceptives, and the exact contraceptives type used, had a significant effect on the time to her first birth. Women who use modern contraceptives and folkloric methods prolonged their time to first birth by about $20.3 \%$ and $63.5 \%$ respectively (survival odds of 1.203 and 1.635 respectively) more than those who practice natural family planning, while women who had never practiced any form of family planning did not significantly differ at the $10 \%$ significance level from women who practiced natural family planning. This is consistent with views by Sobotka, (2004) and Murphy (1992, 1993) who revealed that, delayed childbearing is associated with the spread of access to modern contraception.

Although statistically insignificant, the impact of age at first intercourse on the time to first birth was positive, indicating that later start of sexual intercourse prolonged the waiting time to first birth: The odds ratio show that a one year delay in first sexual intercourse results in an increase at a rate of $3.4 \%$ in the age at first birth. This implies that, women with higher ages at first sexual intercourse are associated with longer waiting times and consequently higher ages at first birth while those who had sexual intercourse early have higher risk of early birth. This may be due to the fact that, the age at which women initiate sexual intercourse marks the beginning of their exposure to reproductive risk, therefore early intercourse may cause early pregnancies. Women in rural settings, and women of Northern Ghana, have waiting times that are $2.4 \%$ and $12.2 \%$ lower than those of their counterparts from urban settings and southern Ghana respectively. This implies that women in rural areas and of Northern Ghana have a slightly high risk of early births than those living in urban and southern areas respectively: albeit not statistically significant at the $10 \%$ significance level.
Additionally, women from traditional homes generally give birth earlier than Muslims, who intern give birth earlier than Christians, albeit not statistically significant at the $10 \%$ significance level. These results are consistent with results from the log-rank test of homogeneity of survival times.

The shape parameter of the log-logistic model is also greater than one, hence the hazard first increase from zero up to a maximum value and then declines back to zero.

The hazard and survival function plots of the age at first birth for the estimated Log-logistic model are shown in Figures 1 and 2 respectively. It shows that, the probability (risk) of having a first birth is highest at about 24 years, after which it declines monotonically as seen in the hazard plot.

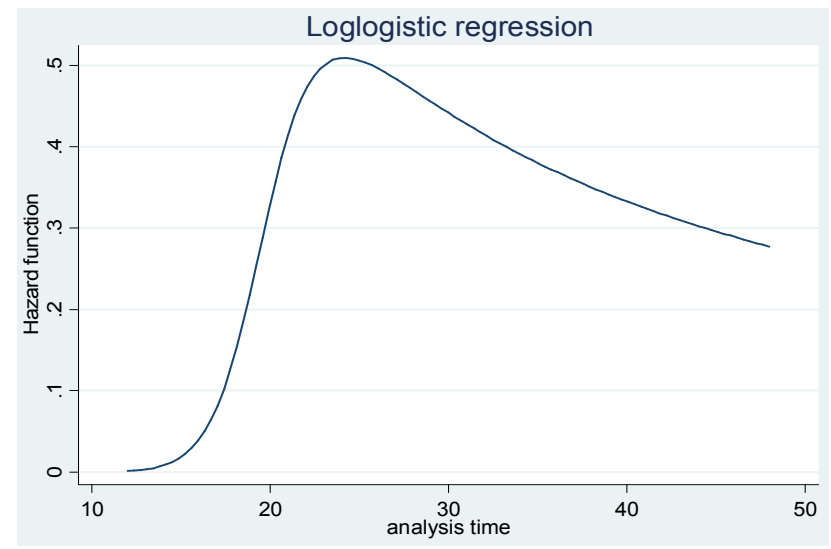

Figure 1. Hazard Plot of the Log-logistic model fitted for age at first birth

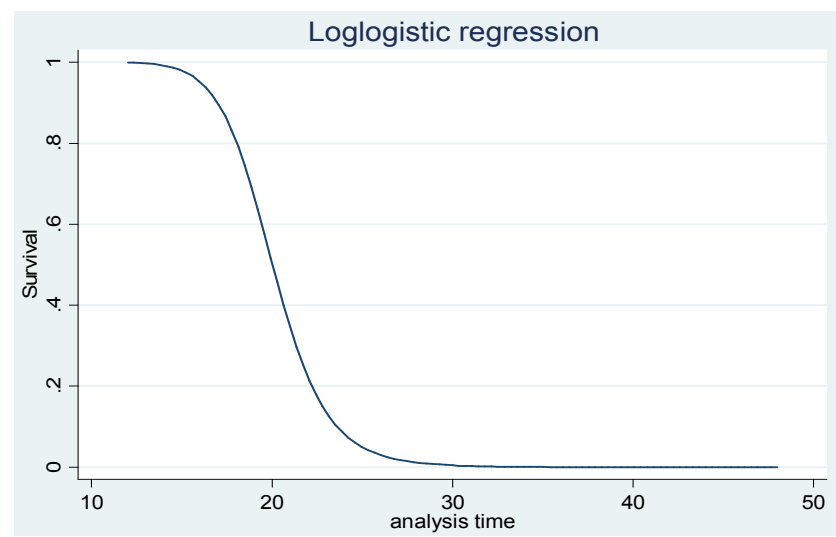

Figure 2. Survival Plot of the Log-logistic model fitted for age at first birth. 


\subsection{Conclusion and Recommendations}

In this study, the statistical distribution and prognostic factors associated with the time to first birth for a cohort of Ghanaian women was investigated. Five parametric survival models were fitted with the covariates, to determine the best parametric survival model that best described the waiting time to first birth of the women. The results showed that, most Ghanaian women gave birth within their twenties. The results also showed that, the time to first birth is best modeled by the log-logistic model. An investigation into the impact of the prognostic factors on the waiting time by the
Log-logistic model evidenced that, the age at first marriage of a woman, her educational level, her wealth status before her first birth and whether the woman practiced family planning were the statistically significant prognostic factors that determined her time to first birth.

\section{Appendix}

Kaplan-Meier Survival curves of test of homogeneity of survival times for age at first birth.

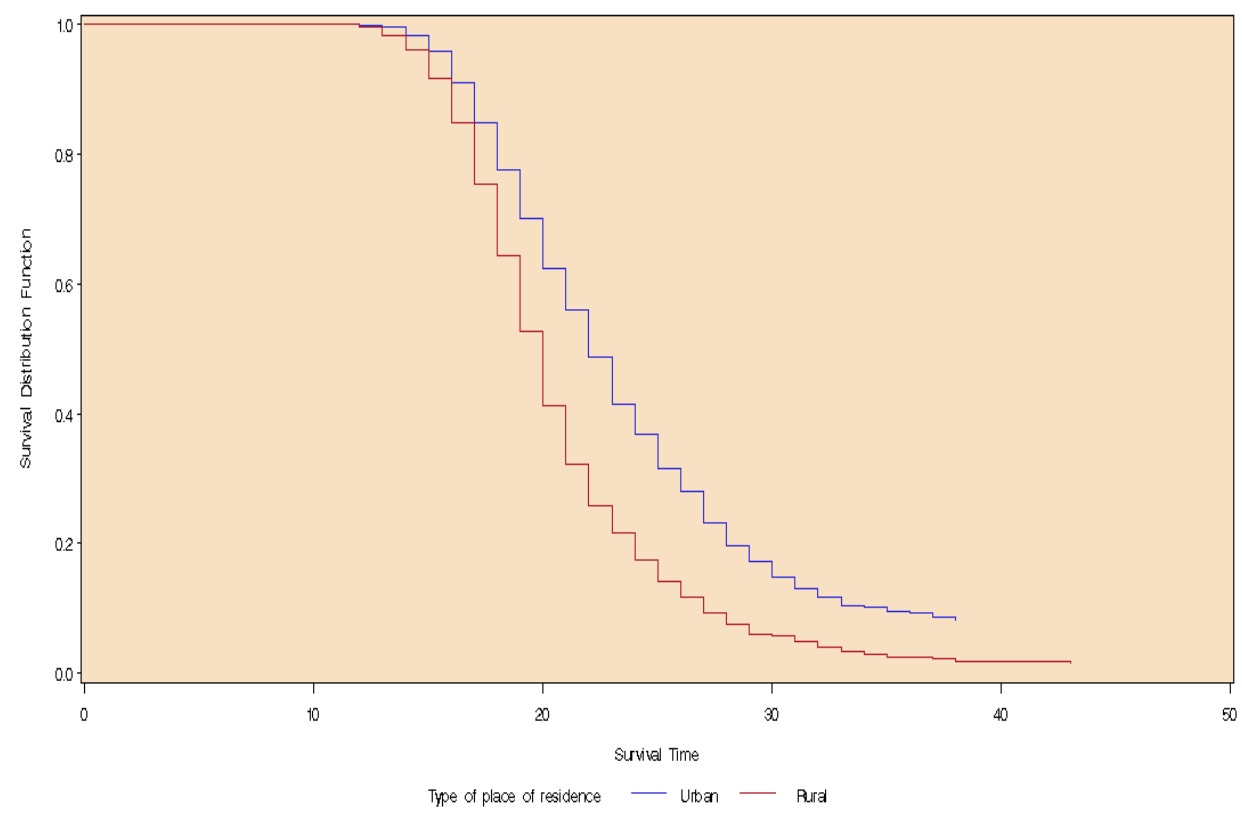

Figure 3. Age at first birth differentials by Type of place of residence (Urban/Rural).

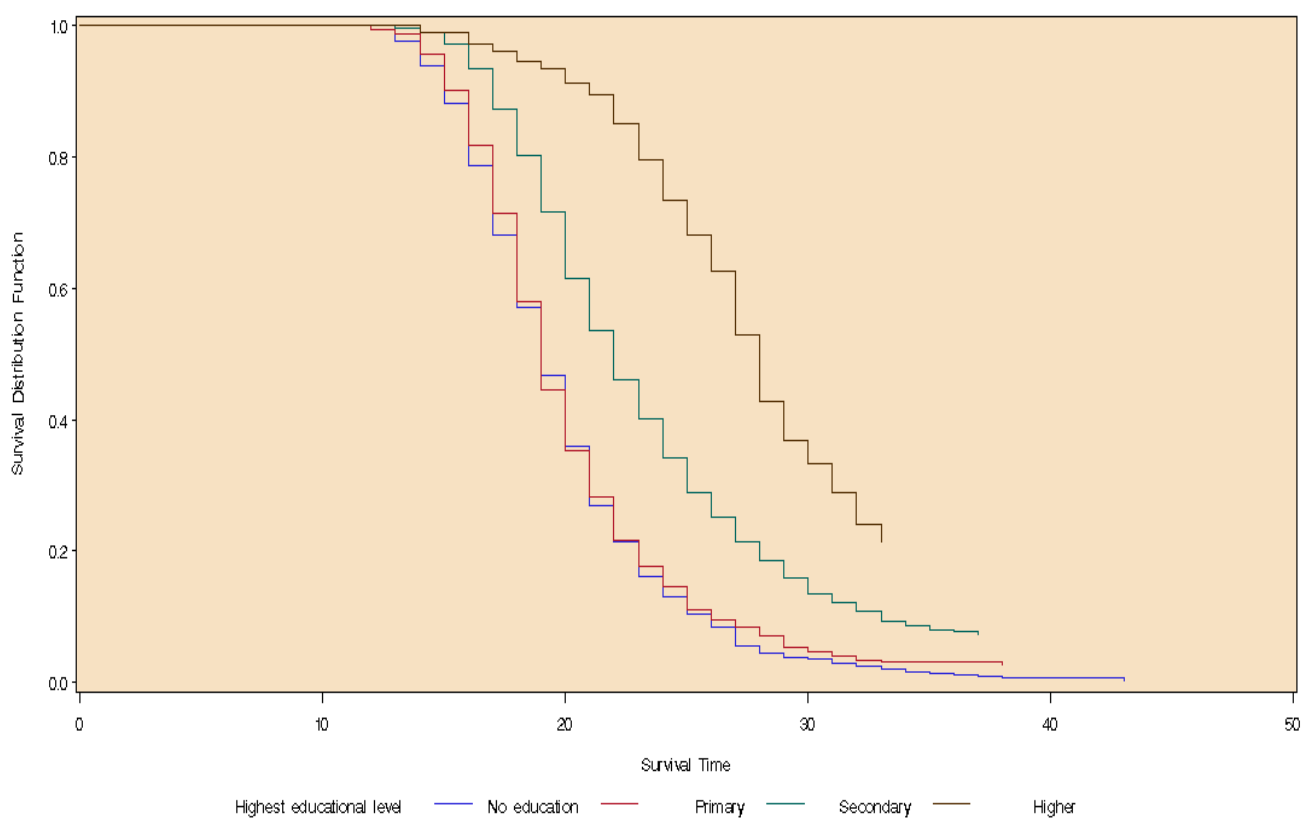

Figure 4. Age at first birth differentials by highest educational level. 


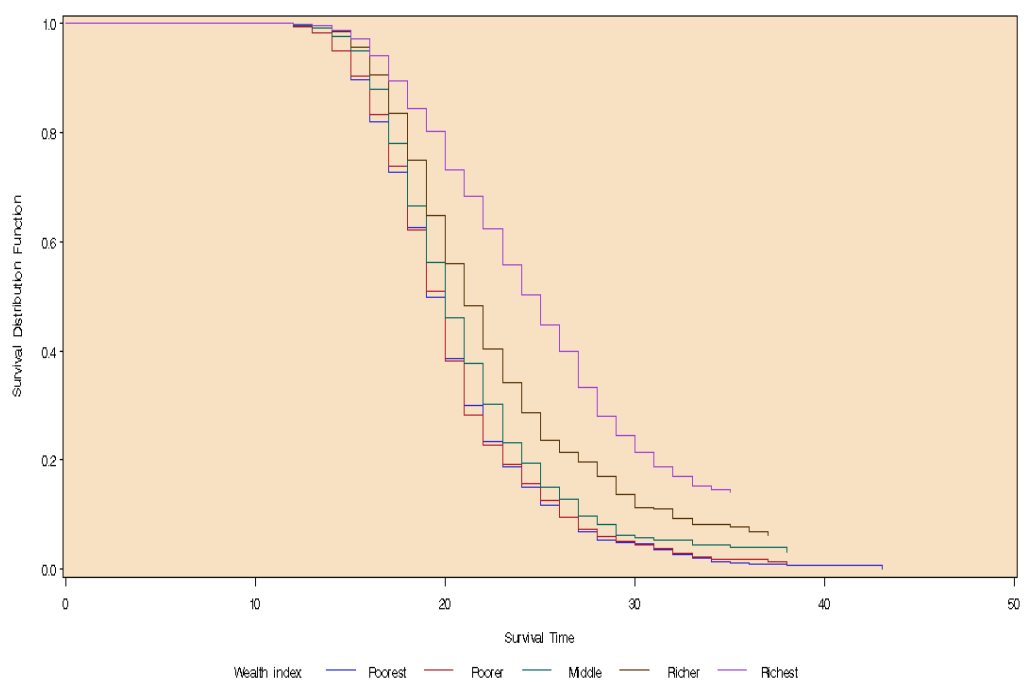

Figure 5. Age at first birth differentials by Wealth index.

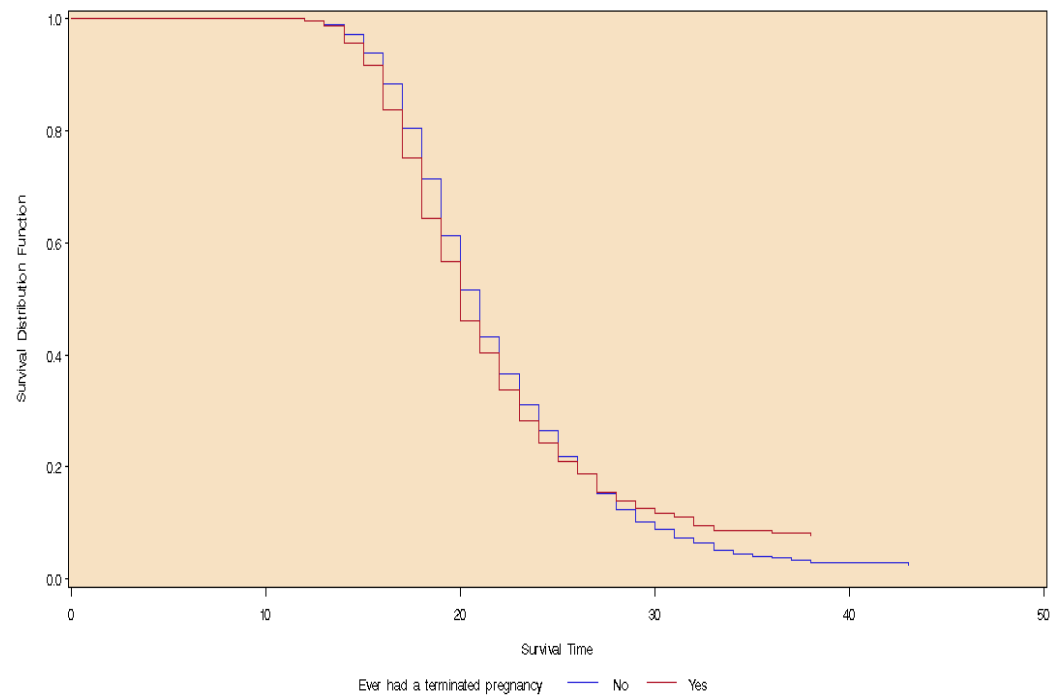

Figure 6. Age at first birth differentials by a whether a woman had ever terminated a pregnancy or not.

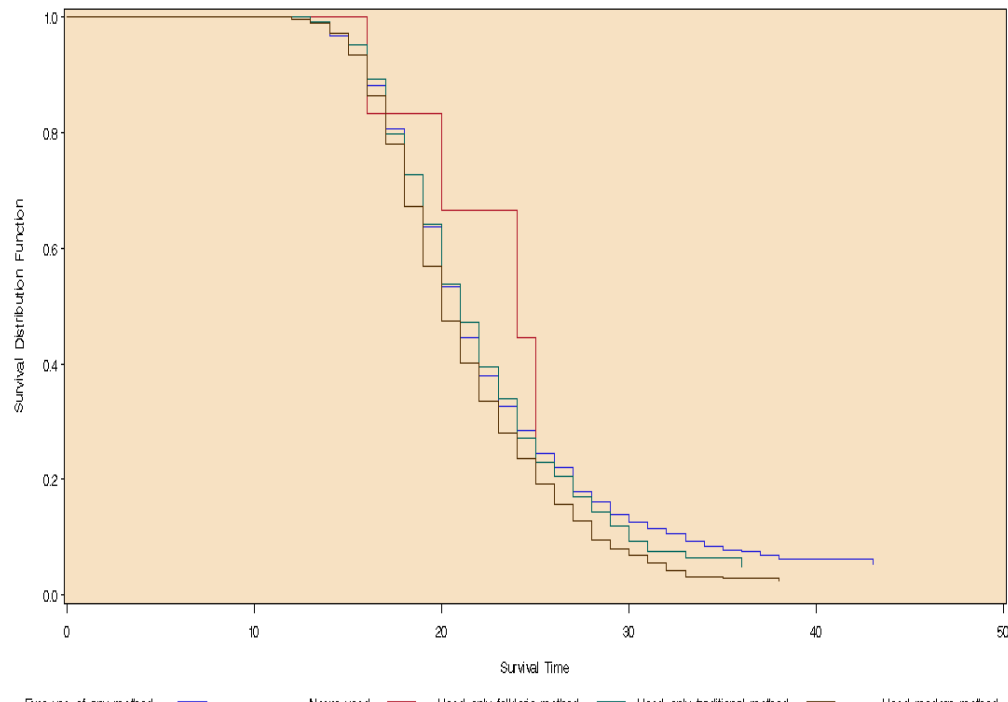

Figure 7. Age at first birth differentials by the type of contraceptives used before first birth. 


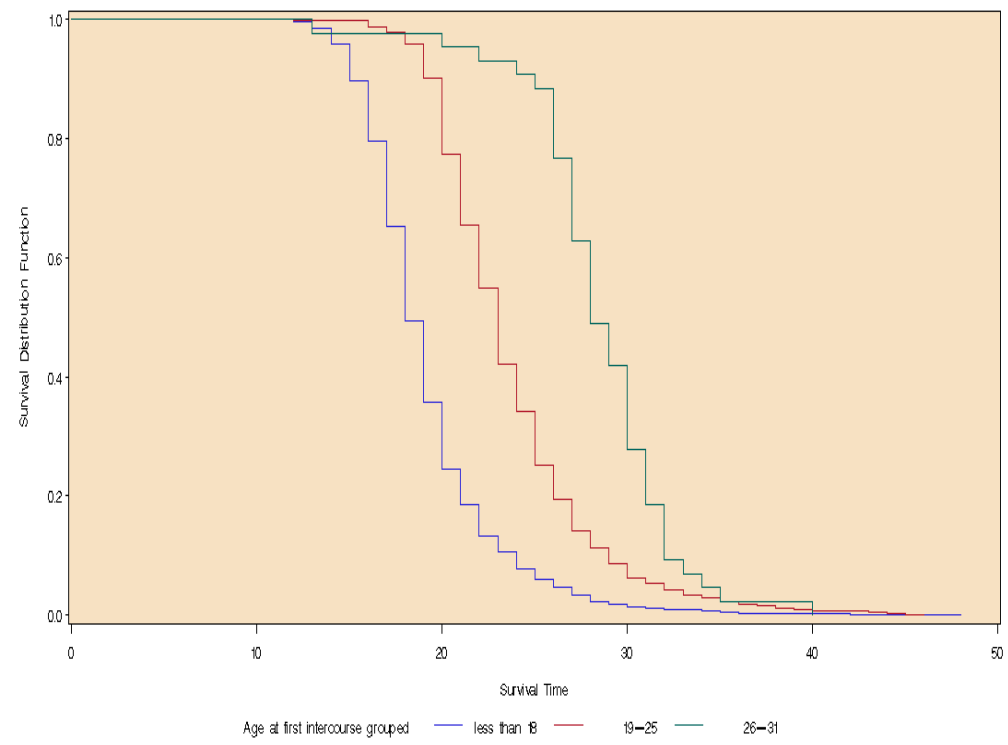

Figure 8. Age at first intercourse grouped with Age at first birth.

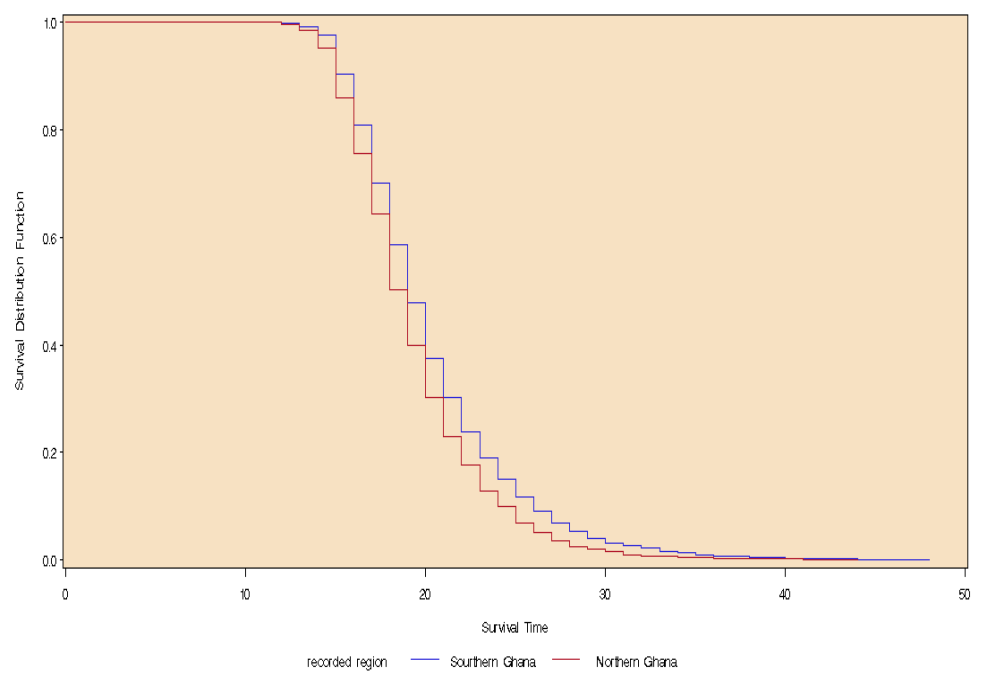

Figure 9. Age at first birth differentials by Region of residence of a woman.

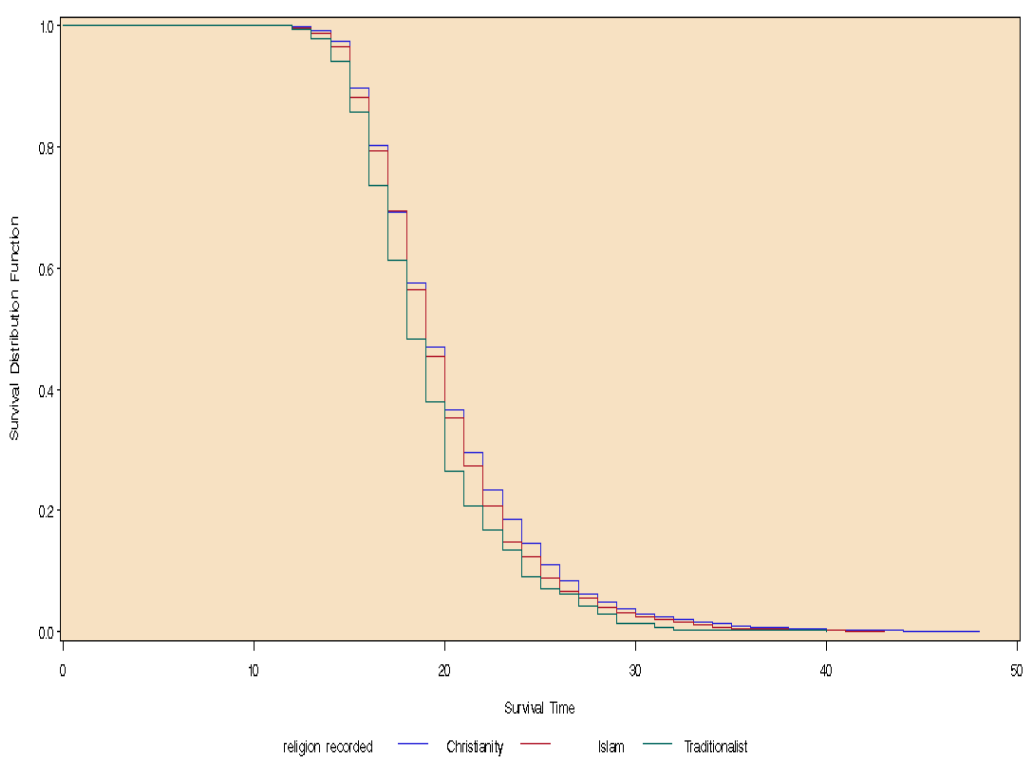

Figure 10. Age at first birth differentials by the religious status of a woman. 


\section{References}

[1] Abhiman D., (2006). Population Evolution Model and its Application for the Estimation of Stable Fertility Rate of Indian States: Demography India, 35(1): 95-110.

[2] Akaike, H., (1974). A New Look at the Statistical Model Identification. IEEE Translation on Automatic Control, AC19:716-723.

[3] Amuedo-Dorantes, C. and Kimmel J., (2004), 'USA: Can the Family Earnings Gap be Reduced by Postponing Maternity?' In: Gustafsson, S. \& A. Kalwij (eds.) Forthcoming. Education and Postponement of Maternity.

[4] Becker S, (2001). Population Growth: American Journal of Public Health, 91(7): 1139-1140.

[5] Blackburn, M. L., Bloom D.E. and Neumark D., (1993). Fertility Timing, Wages and Human Capital. Journal of Population Economics, 6: 1-30.

[6] Bloom, D. E. and Trussel J., (1984). What Are the Determinants of Delayed Childbearing and Permanent Childlessness in the United States? Demography, 21 (4): $591-$ 609.

[7] Cigno, A. (1991). Economics of the Family. Oxford: Oxford University Press.

[8] Cigno, A. and Ermisch J., (1989). A Micro -Economic Analysis of the Timing of Births. European Economic Review, 33 (4): 737-60.

[9] Fisher, B., (1991). Affirming Social Value, Women without Children in Maines: D. R. Social organization and social process, essays in honour of Anselm Strauss.

[10] Gillespie R., (2001). Contextualising Voluntary Childlessness within a Postmodern Model of Reproduction: Implications For Health And Social Needs. Critical Social Policy, 21(2).

[11] Gustafsson, S. and Wetzels C., (2000). Optimal age at maternity in Germany, Great-Britain, the Netherlands and Sweden.' In: Meulders, D. (ed.) Gender and the Labor Market. Econometric Evidence on Obstacles in Achieving Gender Equality. Applied Econometric Association Conference Series, London: Mac Millan.
[12] Gustafsson, S. S., (2001). Optimal Age at Motherhood: Theoretical and Empirical Considerations on Postponement of Maternity in Europe. Journal of Population Economics, 14: 225-247.

[13] Hagman M., (2001). The world in 2050,More crowded, urban and aged:Bulletin of the World Health organization, 79(5): 484 .

[14] Kasarda, J. D., Billy J.O.G. and West K., (1986). Status Enhancement and Fertility, New York.

[15] Kohler H.P., BillariF. C. and Ortega J. A., (2002). The emergence of lowest-low fertility in Europe during the 1990s: Population and Development Review, 28 (4): 641-680.

[16] Kravdal, O., (1994). The Importance of Economic Activity, Economic Potential and Economic Resources for the Timing of First Births in Norway. Population Studies, 48 (2): 249-67.

[17] Lisle L., (1996). Without Child, New York: Routledge.

[18] Logubayom I. A., and Luguterah A., (2013). Survival Analysis of Time to First Birth after Marriage. Research on Humanities and Social Sciences, 3 (12): 2222-2863.

[19] MacInnes J., (2003). A Promising Relationship. Sociology and Demography.

[20] McAllister F. and Clarke L., (1998).Choosing Childlessness in London. Family Policy Studies Centre.

[21] Murphy M., (1992). Economic models of fertility in post-war Britain: A conceptual and statistical re-interpretation. Population Studies, 46 (2): 235-258.

[22] Murphy M., (1993).The contraceptive pill and women's employment as factors of fertility change in Britain 1963-1980: A challenge to conventional view. Population Studies, 47 (2): 221-243.

[23] Peto R. and Peto, J., (1972). Asympotically Efficient Rank Invariant Procedure. Journal of Rural Statistical Society, Series A, 135: 185-207.

[24] Schwarz, G. E., (1978). Estimating the Dimension of a Model. Annals of Statistics, 6:461-464.

[25] Sobotka T., (2004). Postponement of Childbearing and Low Fertility in Europe: $\mathrm{PhD}$ thesis, University of Groningen, Dutch University Press, Amsterdam. 